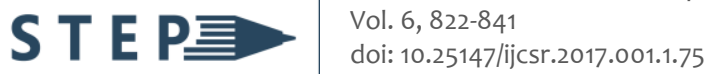 \\ https://stepacademic.net
}

\section{Short Paper \\ Adopting Technology Environment Organization Framework in Virtual Learning through Cloud Computing of Higher Education Institution}

\author{
Amanda Jane C. Menta \\ Lyceum of the Philippines University, Philippines \\ ajanementa@gmail.com
}

Date received: June 24, 2021

Date received in revised form: August 26, 2021; August 30, 2021; September 3, 2021

Date accepted: September 7, 2021

Recommended citation:

Menta, A. J. C.(2022). Adopting technology environment organization in virtual learning through cloud computing of higher education institution. International Journal of Computing Sciences Research, 6, 822-841. doi: 10.25147/ijcsr.2017.001.1.75

\begin{abstract}
Purpose - This study intends to adopt the Technology Environment Organization framework in virtual learning through cloud computing in a higher education institution that will streamline the operation of education.
\end{abstract}

Method - A systematic review using descriptive research was presented highlighting the model of the TEO framework in adopting cloud-based computing implementation in the educational system of the HEls. The study features the critical success factor affecting cloud computing implementation which can be a key point as guidelines and step to embrace technological advancement in the field of education in the Philippines.

Results - The study is appeared to contribute to the organization of higher education institutions in the Philippines to make informed decisions relevant to the advancement of cloud technology service selection and deployment processes. The migration of cloud computing implementation in developing countries is proven successful in achieving the benefits of reducing IT cost, scalability, business continuity, collaboration efficiency, easy management and access, complexity, and compatibility. Thus, the Philippines is admissible to a strategic implementation to widen and improve adopting cloud services. 
Conclusion- Adoption of cloud computing in higher education institutions is an alternative solution in streamlining and managing the educational system infrastructure.

Recommendation - Considering the critical success factor affecting cloud computing implementation the TEO framework is a strategic approach to embrace technological advancement in the Philippines.

Practical Implication - The use of cloud computing in the virtual learning of the HEls has been proven effective in the educational operation considering the critical success factor with the Technology Environment and Organization methods. This aligns with new educational system development in improving the infrastructure of the learning platform of the HEls into more advance and accessible features of the learning delivery through its stakeholders.

Keywords - cloud computing infrastructure, technology environment organization framework, critical success factor of cloud, cloud architecture components

\section{INTRODUCTION}

In today's world, the global use of high-end electronic technology in the Datacenter infrastructure has increased significantly. This trend has developed the Information Technology competition and the need for businesses to expand into different areas to sustain their business continuity through sending emails, sharing repositories, accessing web services, and the internet. The electronic management platform is the main service that promotes the application of the school management system that composes of delivering educational content, the connection with students and professors, communication of administration and non-teaching staff. However, there are several concerns and difficulties in capacity improvement, bandwidth and internet connectivity, hardware and software platform innovation, security implementation, disaster, and recovery backup management (Fenton, 2011).

Such problems result in the difficulty of the mainstream school system with overpopulated classes, cuts in funding, shortages of academically trained, and everchanging expectations. Nonetheless, the application of digital technology innovation called cloud computing will overcome these biggest challenges. Cloud computing is a delivery of services through a web-based platform that is installed anywhere, it can be virtually shared to offer new solutions not found in conventional information technology (IT) to educational system environments. Cloud computing will feature a streamlined operation of education with the capability to concentrate more on the management of students and faculty that serves to deliver the teaching and learning activities instead of IT structures and software systems. This kind of technology is expected to solve multiple 
institutional problems and challenges in minimizing deployment and maintenance costs, enhancing repository data protection, enhancing the versatility of global collaboration, and accessibility without the installation process in the individual computer (Eskineb et al., 2014). However, the procedure of implementation will depend on the data transfer of the organization over the internet and will not be as fast as expected because of the bandwidth throughput requirement. Moreover, the advantage of implementing cloud applications is sometimes being neglected by some organizations due to the traditional belief of some IT professionin administering and protecting the physical set-up of the datacenter than trusting service providers (Enslin, 2012).

This study intends to provide a systematic review of a TEO framework in adopting cloud-based computing implementation in the educational system and subsequently identifying its significant benefits of shifting to the traditional data center into a cloud computing environment setup of an organization in a particular setting of the HEls. Also, it aims to improve the applicable cloud computing deployment in any organization. This study will classify the suitable technology planning and standard conceptual framework of leading factors affecting the cloud computing implementation intended for Educational Institutions. Subsequently, the critical success factor or CSFs of cloud infrastructure design will be identified and the way such frameworks were highlighted by the organizations will be examined.

\section{LITERATURE REVIEW}

The global use of high-end electronic technology in the Datacenter infrastructure has increased significantly in all types of business organizations including the higher education institution. This trend has developed the Information Technology competition and the need for the institution to expand into different areas to sustain its continuity. To address this need, there is a necessity for efficient use of resources in the data center towards operational excellence in data migration, virtualization, and data protection through cloud implementation. It is the ability to deliver cloud services from software and application, and the hardware appliance such as data storage and transferring of power over the internet of any type of business organization.

According to Moore (2019), almost $80 \%$ of the enterprise will shut down the traditional data center and transform it into cloud computing infrastructure by 2025. This will allow the organization by replacing the application and hardware, based on network latency that plays a key role to hold all the data of a company. Cloud computing has been defined as its most significant feature to provide an online repository service, broad access network, measured service, pooling, resource, and scalable provisioning of services. All these features do not limit its functionality by any type of organization particularly for the institution in delivering education. The percentage of workload in the cloud has raised to $79 \%$ in the year 2019 as reported by the State of Cloud Report (Soni, 
2019). The significant development in the usage of cloud networks in the enterprise is evidence of business performance acquired through cloud computing thus will also create financial and operational benefits (Algrari, 2017).

Despite the gaining popularity of cloud computing, it is evident that there is a broad category of cloud services that an organization can adopt. In a typical environment of the IT infrastructure, the deployment and management of applications can be complicated and a time-consuming process that requires full technical expertise and effort of both provider and end-user. The acquisition of cloud computing does not administer vendor frameworks to define the platform setup, installations, and runtime device preferences, as well as policies regulating automatic resource adaptation (loulloudes et al., 2015). The diverse conceptual model of implementing sustainable cloudbased infrastructure in the form of a structured architecture, providing comprehensive control of virtualized cloud resources to create cloud migration through its different architecture structure such as SaaS (Software as a Service), Paas (Platform as a Service), laaS(Infrastructure as a Service), and DaaS (Data as a Services) (Buyya\&Gill, 2018).

\section{Architecture Components of Cloud Computing}

Software as a Service (SaaS). This is a software tool application of distribution structure that permits a computer to access the data files through the web browser as long as connected to network access of the internet. The software provider design a web-based model to manage and host the servers, databases, and program code to communicate with the application. As stated by Astri (2015), it is an application that hosts and administrators can use in their data centers. Those users should be able to grant secure access to the web application. SaaS providers are also merging their operations as their expanding services with PaaS or laaS.

Platform as a Service (Paas). PaaS is an architecture component of the cloud that features a full framework for customer service creation over the cloud-based network. The framework of this platform is designed to provide everything for the users through designing, deployment, testing, and development application to the cloud setup. This model is used to set up a higher service level such as SaaS Application and Services, and Infrastructure as a Services (IaaS). Through this, clients can build web applications on their computers without arranging the hardware and software resources. Provided complete control over the applications to run and deploy. Services providers have an option to use the different platforms such as integrated OS, middleware, and application software set-up; on the customer side, API (application programming interface) provides user-side package service and consumers use the Platform via API (Singh, 2013). The cost 
of a PaaS is very small as compared with the data center based software development platform.

Infrastructure as a Services. The structure of laaS is managed with associated and identified over the network through the software and hardware transfer. The hardware platform of laaS is usually composed of servers, storage, and network appliance to collaborate with the function of the software. On the software side, the main application platform is listed including operating systems, virtualization software, and file transfer system. This is the technological change of dynamic network hosting that will provide access to the services on-demand to IT management without requiring any longstanding commitment. As part of laaS implementation, the provider has minimal manipulation of managing the installation other than keeping the data center operational in contrast to PaaS. Thus, the implementation and management of the system's software require to be implemented and operated by IT people similar to the traditional environment of the data center (Majadi, 2016).

Data as a Services (DaaS). As stated by Toth \& Ge(2021), DaaS is a classified architecture at a conceptual model of cloud computing that delivers the data through storage in a virtualization distribution in a separate cloud service known as data storage service. Considering this architecture component, it can be classified as part of laaS. However, it allows the provider to compensate for the extended services that need to conform to the service design rather than the amount of per license for the entire database including the conventional storage interfaces including RDBMS and file systems.

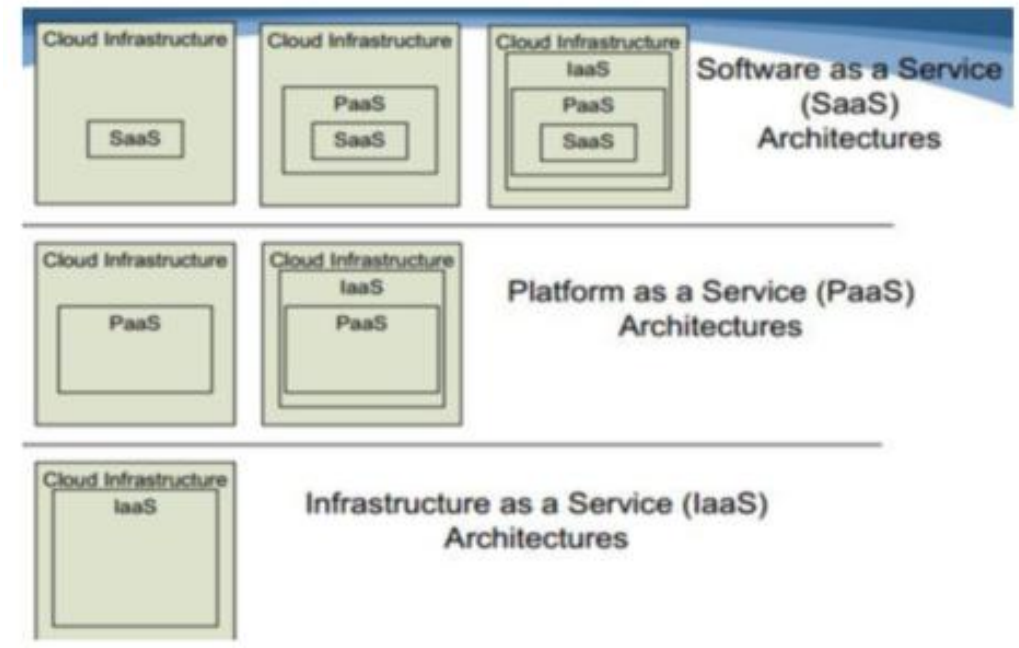

Figure 1. Cloud Computing Service Model Environment(Astri, L. Y., 2015)

Applications can be accessed in three-tier models of cloud-based computing. Services are accessible through the communication medium of the web of the public cloud, such as social networks, email services, images sharing, and server documents. 
Another environment is the private cloud wherein the service is accessible in a private network environment. The use of the public and private networks is called hybrid cloud which mainly operates on-premise servers and third-party services of the public cloud. In addition, considering architecture is another key point of cloud computing. The architectural design has two different layers, the layer that works in on-premise physical resources such as data and backup storage and application servers. This serves as the layer management for the sharing of resources, storage space, and protection context separately by the virtual level.

\section{Cloud Computing Implementation CSFs Categories}

The CSF is the common term in the cloud computing environment that differs as a Critical Success Factor. This aspect needs to be evaluated and examined when a company is involved in any type of business organization in considering the inquiries performed to run performance components of a cloud-based solution. This is a vital component in any operation to ensure the effectiveness of an organization's implementation process. As a result, CSFs are all factors that need to be considered in applying the advancement of the successful implementation of technology.

Technology Context. The Technology dimension refers to cloud computing technology's physical appearance. It is one of the core principles when introducing new technologies and has been taken as the main indicator for incorporating technological innovation in the Information System (IS). The current literature shows that there is a broad number of elements to be examined to operate the technical context internally.

Cost-Effectiveness. The cost of introducing cloud computing technology in any organization has been identified as a significant matter. The larger the day-to-day operation of a business institution, the greater demand in investment for the IT infrastructure as it holds massive data. Consequently, the portion of the population is a major factor in cost investments in the implementation of acquiring new information technology infrastructure. As stated by Naveed \& Ahmad (2019), Cloud is evolving infrastructure management of IT used in any field of the organization specifically the higher education institution due to the competitive pricing model it has. This is supported by its features of an integrated framework built on an open-source program and reduced device use expense. Cloud computing is the new and most exponentially growing IT market. The geographical delivery capability, cost-efficient in an automatic form of systems, and open source applications make it a desirable choice for higher educational institutions through interactive and vibrant learning experiences. As highlighted by 
Dimitrov and Osman, (2014), that cost-effectiveness is the primary reason affecting the IT Managers in determining cloud computing service opportunities. As such cloud computing also contributes to the lower cost of the applications since organizations are no longer have to purchase different sets of software for each device. Furthermore, the substantial costs in operating an IT infrastructure will also affect the use of energy by lowering the power consumption as it doesn't deploy the inhouse datacenter.

Security. One of the concerns of all IT organizations that hinder adopting cloud computing is the level of security when the data is transmitted to the networks of local organizations. However, there are more and more standard organizations set to allow safety requirements in cloud computing to improve interoperability and stability, minimize repetitive expenditure, or replicate innovation. Thus, creating a security architecture for cloud computing, and systematically perform research on cloud security main technologies such as firewall, security measures of architecture, and cloud computing security standard authentication (Chen et al., 2012).

Reliability. The cloud computing adoption of the organization will depend on the purpose and willingness of implementing cloud computing in the operations of IT infrastructure considering the reliability factor. Optimizing the cloud-based solution in the data center will ensure the reliability of the whole system's function. Reliability is defined as the probability of the uptime of the service deliverable by $99.9 \%$ under a given set of conditions wherein a given item will perform its intended function for a given period. Reliability in the cloud means how the cloud is available to provide the services even if multiple of its components fail. A cloud will become more reliable if it is more tolerant to faults and more adaptable to changing situations. A cloud that is completely free of failures or resistance to failure is impossible to have, however, a high risk of reliability is expected through the capacity and lower downtime period to assure the continued operation of the system without interruption or failure (Kaur\& Kumar, 2015).

Speed performance. With the rapid advancement of cloud computing and network technologies, cloud service has a remarkable impact on the performance of future information technology infrastructure. As mentioned by Duan (2017), a thorough evaluation of the performance of cloud services is crucial and beneficial for service providers and consumers. In delivering the cloud services, the infrastructure design and advancement of technology could be measured using speed as one of the elements in representing the daily operation process of business, effective management, two-way customer communication, and accessibility to mobile information in the market. The entire set-up of cloud computing requires a high bandwidth speed of internet connection 
which can be the most challenging part since unstable internet connection can be experienced. Therefore, performance factors were significant obstacles in cloud adoption, and development is highlighted as performance challenge is significant and discipline needs to continue innovating to meet that challenge (Paliwal, 2014)

Complexity and Compatibility. One way to conclude in shifting to cloud computing is the dimensions of which organizational leaders have an advanced level of expertise in terms of cloud complexity and compatibility of data transferring, interface design workflow, and 100\% system functionality (Kandiletal., 2018). As highlighted by Yoo and Kim (2018), complexity and compatibility were not identified as important factors to influence technology implementation. Thus, the increasing compatibility performance affects the deployment target and the strategic implementation of the cloud environment in an effective way.

Organizational Context. As defined by Baker (2011), the organizational context refers to the characteristics and resources of the company that includes the correlation of the people arrangements, inter-company communication protocols, ratio of the firm, and the sum of the allocated budget that affects the adoption and implementation decision. This context involves the recovery planning of data and business continuity, top management support, and knowledge awareness in terms of cloud computing(Tam, M. \& Lin, T.T.C).

Recovery planning of data and business continuity. The backup recovery plan of data is the most crucial element of a company particularly in implementing cloud computing in the technology's structure that assures the business function of the organization. Hence, cloud storage infrastructure with a disaster recovery policy of all kinds must be prepared. As explained by Jorrigala (2017), another strategy to implement is disaster recovery and back-up systems in the data center thus it is capable of recovering and continuing business using cloud services. The service provider of cloud computing should provide a plan in service implementation and relocation of data as a backup to help the organization solve data loss and restore system functionality to perform after an incident (Bedward\&Fokum, 2014).

Top Management Support. The support of higher management performs the major function in the creation, support, and provision of adequate resources to implement new technologies. This process can provide resource integration and business model reengineering as part of the organizational structure that involves factors such as the firm size, the characteristic of human resources, and the adoptable of the management 
structure (Yoo\& Kim, 2018). As researched, higher management support has been the biggest contributing factor in adopting a cloud computing system that measured priorities among each decision, factor, and attribute. Therefore, such decision-makers agree to implement a cloud computing system, considering compatibility with existing systems is necessary to preserve legacy system stability and its cost-efficient of its implementation. However, this factor can be the main challenging issue in the strategy of implementation in particular to gain adequate financial return of investment and technological skills.

Knowledge Awareness. Awareness of knowledge refers to the organization's prediction, interpretation, and comprehension of the importance and possibility of adoption of technology. As revealed by Alatresh et al. (2017), several studies attempted to describe the factors impacting business organizations' of cloud computing considering the framework utilized in understanding computing, TAM (Technology Acceptance Model)is the most significant structure used. It was suggested that awareness should be part of the implementation development to facilitate the incorporation of cloud-based computing in everyday business operations.

Environment Context. The last framework of TEO is the environmental context which is taken into account directly in the organizations' decision-making behavior where a corporation conducts business such as its market, its rivals, and its policy dealings (Oliveira\& Martins, 2010). This also includes the structure of the market where will depend on the suppliers offering technology services, and the regulatory environment (Baker, 2011). According to several studies, such elements influence the level of technological innovation of the business thus statistically significant factors for the implementation of cloud computing in one organization.

Competitive Pressure. Typically, the competition within the industry is perceived to have a positive impact on IT Infrastructure implementation particularly when technology participates with an active competition where it is a strategic fundamental to deal with advanced technology offerings in the market. Competitive pressure has been one of the main considerations when adopting cloud computing. The substantial and beneficial relationship of competitive pressure and adoption means that when competitors incorporate cloud-based environment as a strategic tool, thus will be a basis to embrace cloud computing to retain a competitive edge. Once the institution has the substantial attributes of agility and innovation, competitors result in dealing with the difficulties and will consider the implementation of the latest technologies by similarly by its competitor (Abdollahzadehgan et al., 2013). 
Governance and Policy. Engaging with cloud providers requires warrant consideration through legal and regulatory requirements. In every acquisition, there is an equivalent rule and law in dealing with a business process as well as the technology change. In cloud operation, data privacy and sovereignty laws and requirements have sprung up all over the entire process (Schaefer et al., 2014). Compliance with these laws and regulations can be complicated, as there are many grey areas and circumstances legally untested, such as what constitutes data export. Thus, it is suggested to obtain legal advice before entering into any cloud arrangements, especially when operating in strictly regulated industries such as financial services or healthcare or when systems constitute personal information. In such a scenario, top management plays a key role in the creation, support, and provision of adequate resources to implement new technologies. In an IT governance perspective which focused on accountability, establishing decision rights, and managing benefit or value, risk, and resources in a cloudbased environment. The procedure could involve resource integration and business model re-engineering. These challenges start from auditing to operation management, IT policy and governance, compliance with regulations, IT strict security and accountability for access management, electronic discovery, privacy, and research results protection. Overall, cloud computing creates business-driven policies and procedures which set the correct degree of investment and controls for cloud services across the project life cycle. This ensures that all cloud-related company spending is aligned with business goals, promotes enterprise-wide data integrity, encourages innovation, and mitigates the risk of data loss or non-compliance with regulations (The Open Group, 2016).

Social Pressure. Social pressure is the direct influence of peers on individuals or the impact who affects the peers by modifying the attitudes, beliefs, or actions to the community or person influencing them. According to Buhtz, Konig, and GrafVlachy(2018), it has been shown that social impact deeply influences human behavior in general and the adoption of information technology. The field of technology adoption research has been introduced with multiple meanings and measures of social impact, contributing to an additional fragmented landscape of constructs that challenges the conceptual integrity of the field. Such social challenges also harm Cloud Computing's deployment decision. Thus, some IT executives may have a negative view of cloud computing technologies.

Trading Partner and Supplier Support. In certain cases, the decision of adopting cloud computing of many organizations will mainly rely on business partners or suppliers provided with the detailed and systematic IT design and implementation tasks of the 
migrating system. As researched by Menychtas et al. (2012), The trading partner and supplier should equip with function broad selection of cloud computing services, sophisticated service discovery, availability and resolution, and one-stop pricing of service packages that is flexible and suitable arrangement depending on the desired set-up of the organization.

\section{METHODOLOGY}

As the systematic review provided, a significant understanding of the factors impacting business organizations' specifically the Higher Education Institution sectors in adopting cloud technology solutions has been identified with its critical success factor criteria. Through the fast development of information technology, there are different variety of cloud deliverable as services have been implemented as a dispensable part of various organizations' information systems. Thus, cloud service efficiency has a direct effect on the performance of the entire future of information infrastructure (Duan, 2017). As a result, various results were obtained, and many scientific theories of adoption were used to describe the adoption such as TEO (Technology Environment Organization), TAM (Technology Acceptance Model, COBIT (Control Objectives for Information Technology), DOI (Diffusion of Innovation), UTAUT (Unified Theory of Acceptance and Use of Technology). These five (5) theoretical frameworks and the combined model showed acceptable explanatory power that is commonly used in adopting cloud computing. Table 1 shows a summary of the reviewed articles. This presents the data with the author, title, year of publication, method of research, and theoretical model used in the studies.

As depicted in Table 1, the most used theoretical model in adopting cloud computing is the Technology Environment Organization framework with a percentage of $64.87 \%$ followed by DOI with $13.51 \%$, TAM and an unspecified model with $8.11 \%$ and the same percentage for UTAUT and Cloud Business model with $2.70 \%$. This percentage is shown in Figure 1 the theoretical model used in other studies particular in considering the adoption of cloud computing. 
Table 1. Summary of Literature Review of Cloud Computing Adoption

\begin{tabular}{|c|c|c|c|c|c|}
\hline No. & Author & Title & $\begin{array}{c}\text { Year } \\
\text { Published }\end{array}$ & $\begin{array}{l}\text { Method of } \\
\text { Research }\end{array}$ & $\begin{array}{c}\text { Theoretical } \\
\text { Model }\end{array}$ \\
\hline 1 & $\begin{array}{l}\text { Alatresh, S.A, Ali, } \\
\text { A.B., Morad Ali } \\
\text { Ambarek }\end{array}$ & $\begin{array}{l}\text { Cloud Computing Adoption } \\
\text { by Business Organization: A } \\
\text { systematic Review }\end{array}$ & 2017 & $\begin{array}{l}\text { Mixed } \\
\text { Methodologies }\end{array}$ & $\begin{array}{l}\text { TAM, DOI, } \\
\text { UTAUT, TEO }\end{array}$ \\
\hline 2 & Lola YoritaAstri & $\begin{array}{l}\text { A Study Literature of Critical } \\
\text { Success Factors of Cloud } \\
\text { Computing in Organizations }\end{array}$ & 2015 & $\begin{array}{l}\text { systematic } \\
\text { review }\end{array}$ & TAM \\
\hline 3 & $\begin{array}{l}\text { Quadri, N.N., } \\
\text { Ahmad, N. }\end{array}$ & $\begin{array}{l}\text { Critical Success Factors for } \\
\text { Cloud-based E-Learning }\end{array}$ & 2019 & $\begin{array}{c}\text { Mixed } \\
\text { Methodologies }\end{array}$ & $\mathrm{n} / \mathrm{a}$ \\
\hline 4 & $\begin{array}{l}\text { Hiran, K.K., } \\
\text { \&Henten, A. }\end{array}$ & $\begin{array}{l}\text { An integrated TOE- } \\
\text { Dolframework for cloud } \\
\text { computing adoption in the } \\
\text { higher education sector: case } \\
\text { study of Sub-Saharan Africa, } \\
\text { Ethiopia }\end{array}$ & 2019 & $\begin{array}{l}\text { Mixed } \\
\text { Methodologies }\end{array}$ & TOE and DOI \\
\hline 5 & Zack Enslin & $\begin{array}{l}\text { Introduction to cloud } \\
\text { computing and control } \\
\text { objectives for information } \\
\text { and related technologies } \\
\text { (COBIT)-mapped benefits of } \\
\text { cloud computing adoption }\end{array}$ & 2011 & & COBIT \\
\hline 6 & $\begin{array}{l}\text { Abdollahzadehgan } \\
\text {, A., Amini, M., Che } \\
\text { Hussin, A. R., } \\
\text { \&Gohary, M. M. }\end{array}$ & $\begin{array}{l}\text { The Organizational Critical } \\
\text { Success Factors for Adopting } \\
\text { Cloud Computing in SMEs }\end{array}$ & 2013 & Qualitative & TOE \\
\hline 7 & $\begin{array}{l}\text { Ayman Mohamed } \\
\text { Nabil AnterKandil, } \\
\text { Mohamed A. } \\
\text { Ragheb, Mohamed } \\
\text { A. Ragheb, Aiman } \\
\text { A. Ragab, } \\
\text { Mahmoud Farouk }\end{array}$ & $\begin{array}{c}\text { Examining the effect of TOE } \\
\text { model on cloud computing } \\
\text { adoption in Egypt }\end{array}$ & 2018 & Quantitative & TOE \\
\hline 8 & $\begin{array}{l}\text { Seok-KeunYoo and } \\
\text { Bo-Young Kim }\end{array}$ & $\begin{array}{l}\text { A Decision-Making Model for } \\
\text { Adopting a Cloud Computing } \\
\text { System }\end{array}$ & 2018 & $\begin{array}{c}\text { quantitative } \\
\text { and } \\
\text { comparative } \\
\text { study }\end{array}$ & TOE \\
\hline 9 & $\begin{array}{l}\text { Ilango Sriram, Ali } \\
\text { Khajeh-Hosseini }\end{array}$ & $\begin{array}{l}\text { Research Agenda in Cloud } \\
\text { Technologies }\end{array}$ & n.d. & $\begin{array}{l}\text { systematic } \\
\text { review }\end{array}$ & $\mathrm{n} / \mathrm{a}$ \\
\hline 10 & $\begin{array}{l}\text { Mark Stieninger, } \\
\text { Dietmar Nedbal, } \\
\text { Werner } \\
\text { Wetzlinger, } \\
\text { GeroldWagner, } \\
\text { Michael A. Erskine }\end{array}$ & $\begin{array}{l}\text { Impacts on the } \\
\text { organizational adoption of } \\
\text { cloud computing: A } \\
\text { reconceptualization of } \\
\text { influencing factors }\end{array}$ & 2014 & $\begin{array}{l}\text { quantitative/ } \\
\text { systematic } \\
\text { review }\end{array}$ & DOI and TAM \\
\hline
\end{tabular}


Table 1. Summary of Literature Review of Cloud Computing Adoption (cont.)

\begin{tabular}{|c|c|c|c|c|c|}
\hline No. & Author & Title & $\begin{array}{c}\text { Year } \\
\text { Published }\end{array}$ & $\begin{array}{l}\text { Method of } \\
\text { Research }\end{array}$ & $\begin{array}{c}\text { Theoretical } \\
\text { Model }\end{array}$ \\
\hline 11 & $\begin{array}{l}\text { Tam, M. \& Lin, } \\
\text { T.T.C }\end{array}$ & $\begin{array}{l}\text { Exploring the organizational } \\
\text { adoption of cloud computing } \\
\text { in Singapore }\end{array}$ & 2012 & quantitative & $\begin{array}{l}\text { Innovation } \\
\text { diffusion } \\
\text { theory }\end{array}$ \\
\hline 12 & $\begin{array}{l}\text { Nabeel Khan and } \\
\text { Adil Al-Yasiri }\end{array}$ & $\begin{array}{l}\text { FRAMEWORK FOR CLOUD } \\
\text { COMPUTING ADOPTION: A } \\
\text { ROADMAP FOR SMES TO } \\
\text { CLOUD MIGRATION }\end{array}$ & 2015 & qualitative & $\begin{array}{l}\text { Cloud } \\
\text { Business } \\
\text { Model } \\
\text { Framework }\end{array}$ \\
\hline 13 & $\begin{array}{l}\text { FarahnazSadoughi, } \\
\text { Omar Ali, Leila } \\
\text { Erfannia }\end{array}$ & $\begin{array}{l}\text { Evaluating the factors that } \\
\text { influence cloud technology } \\
\text { adoption-comparative case } \\
\text { analysis of health and non- } \\
\text { health sectors: A systematic } \\
\text { review }\end{array}$ & 2019 & qualitative & TOE \\
\hline 14 & $\begin{array}{l}\text { Andreas } \\
\text { Menychtas, Sergio } \\
\text { Garcia Gomez, } \\
\text { Andrea Giessmann, } \\
\text { Anna Gatzioura1, } \\
\text { Katarina } \\
\text { Stanoevska, } \\
\text { Jürgen Vogel, and } \\
\text { Vrettos Moulos }\end{array}$ & $\begin{array}{l}\text { A Marketplace Framework } \\
\text { for Trading Cloud-Based } \\
\text { Services }\end{array}$ & 2012 & $\begin{array}{l}\text { systematic } \\
\text { review }\end{array}$ & $\mathrm{n} / \mathrm{a}$ \\
\hline 15 & $\begin{array}{l}\text { Omar Al Hujran, } \\
\text { Mutaz M. Al-Debei, } \\
\text { Mahmoud } \\
\text { Maqableh }\end{array}$ & $\begin{array}{l}\text { Challenges of Cloud } \\
\text { Computing Adoption From } \\
\text { the TOE Framework } \\
\text { Perspective }\end{array}$ & 2018 & Qualitative & TOE \\
\hline 16 & VyshnaviJorrigala & $\begin{array}{l}\text { Business Continuity and } \\
\text { Disaster Recovery Plan for } \\
\text { Information Security }\end{array}$ & 2017 & Qualitative & $\mathrm{n} / \mathrm{a}$ \\
\hline 17 & Michael McKinnie & $\begin{array}{l}\text { Cloud Computing: TOE } \\
\text { Adoption Factors By Service } \\
\text { Model In Manufacturing }\end{array}$ & 2016 & $\begin{array}{c}\text { Mixed } \\
\text { Methodologies }\end{array}$ & TOE \\
\hline 18 & $\begin{array}{l}\text { Almekhlafi, N., Al- } \\
\text { Hashedi, A., } \\
\text { Mohsen, A.M., } \\
\text { Othman, M.T.B. }\end{array}$ & $\begin{array}{l}\text { Cloud Computing Awareness } \\
\text { among Practitioners in } \\
\text { Yemeni Universities: An } \\
\text { Exploratory Study }\end{array}$ & 2018 & Qualitative & $\mathrm{n} / \mathrm{a}$ \\
\hline 19 & $\begin{array}{l}\text { AlalaaNumanTashk } \\
\text { andi, Ibrahim M Al- } \\
\text { Jabri }\end{array}$ & $\begin{array}{l}\text { Cloud Computing Adoption } \\
\text { by Higher Education } \\
\text { Institutions in Saudi Arabia: } \\
\text { Analysis Based on TOE }\end{array}$ & 2015 & $\begin{array}{c}\text { mixed } \\
\text { Methodologies }\end{array}$ & TOE \\
\hline 20 & Hakim, Z. & $\begin{array}{l}\text { Factors That Contribute to } \\
\text { The Resistance to Cloud } \\
\text { Computing Adoption by Tech } \\
\text { Companies vs. Non-Tech } \\
\text { Companies }\end{array}$ & 2018 & Qualitative & TOE \\
\hline
\end{tabular}




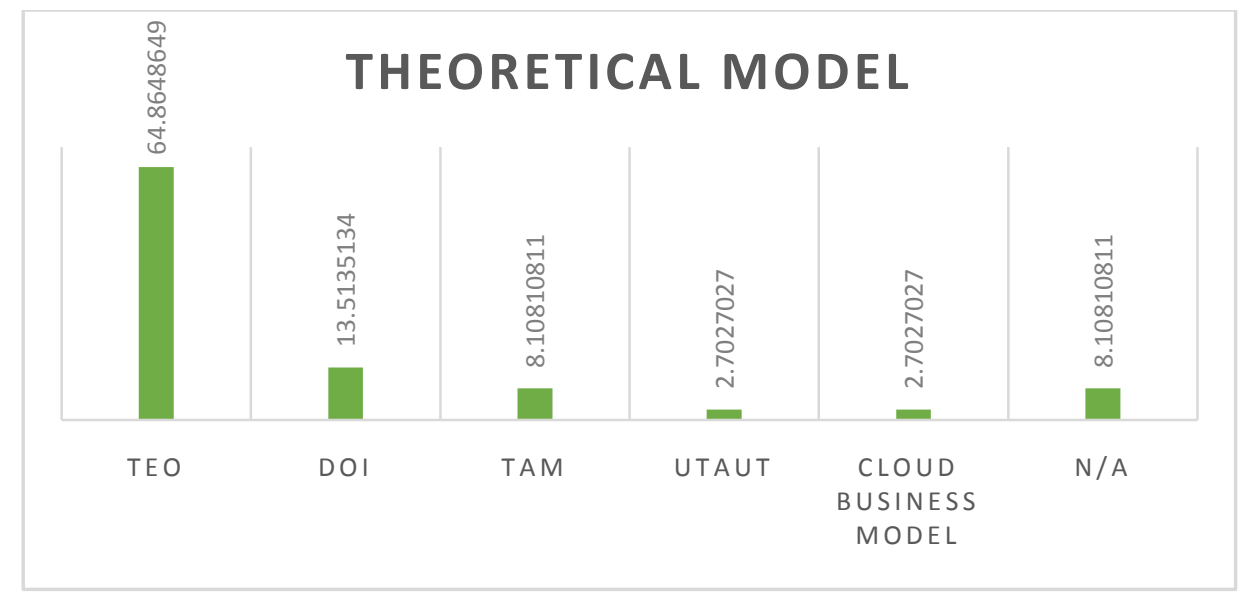

Figure 2. Theoretical Model

In this consideration, the key-driven decision-making framework in implementing a cloud-based solution system was developed according to the TEO Framework which lists as the popular model used in the reviewed literature as shown in Figure 2. The feature of this framework was developed according to the three-tiered architecture context to enable intuitive and rapid decision-making for top management, including decision factors, areas, and attributes. All the analysis and investigation found from prior research regarding the adoption of cloud-based computing were collected and considered as options for the contributing factors in the theoretical framework of TEO. Those factors and considerations were placed accordingly by nature into factors and attributes in the framework scheme as shown in Figure 3.

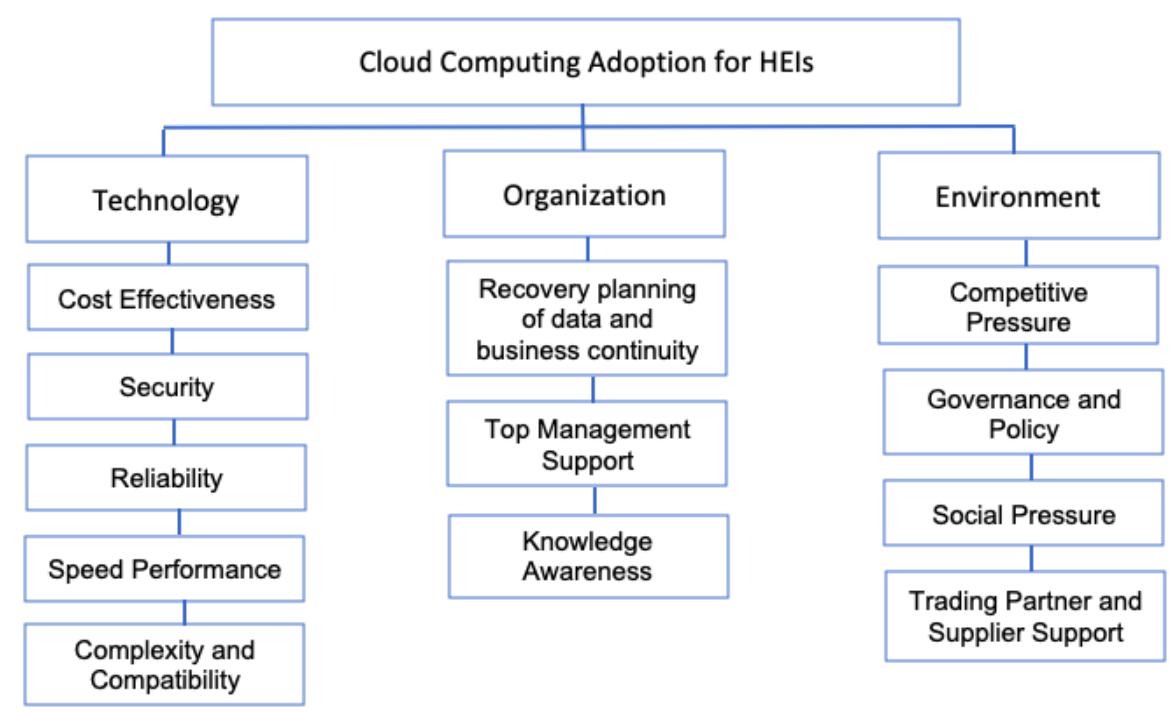

Figure 3. The decision-making hierarchy structure using TEO Framework 


\section{RESULTS AND DISCUSSION}

The study is beneficial to contribute to the organization of higher education institutions in the Philippines to make informed decisions relevant to the advancement of cloud technology service selection and deployment processes. The migration of cloud computing implementation in developing countries is proven successful in achieving the benefits of reducing IT cost, scalability, business continuity, collaboration efficiency, easy management and access, complexity, and compatibility. Thus, the Philippines is admissible to a strategic implementation to widen and improve adopting cloud services. As part of the research, analysis is the development and deployment of the current cloud computing deployment in SME's organizations in the Philippines that requires an in-depth investigation in obtaining a clear apprehension of the success rate of implementation. The result would be beneficial for the HEls to create an assessment of the current state of implementation and take the appropriate steps to enhance technology management through cloud computing. Overall, this study intended to contribute to the current information about the innovative advancement of cloud computing technology by incorporating the best systematic system's approach in cloud adoption in improving resource utilization including the changes in the profit.

\section{CONCLUSIONS AND RECOMMENDATIONS}

The systematic review of this research provides a significant insight from the consolidated study proving that the adoption of virtual learning through cloud computing of higher education institutions is an alternative solution in streamlining and managing the education system in the Philippines. Moreover, the most identified theoretical model is the Technology Environment Organization was the commonly adopted framework used to align with the critical success factors of cloud computing application to highlight the impact such as reducing IT cost, scalability, business continuity, collaboration efficiency, easy manage and access, complexity, and compatibility (Sether, 2016). Considering the impact and the effectiveness of cloud computing to manage and streamline the education system of the HEls was a successful endeavor in transforming the learning management of the Education System (Hiran \& Henten, 2019). Regardless of the limited resources in terms of duration, location, and deployment evaluation, the research outcome provides a valuable contribution for the Higher Education Institution to be the new transition of the virtual learning to contributes and support with other research works. In the engagement of technology in the field of education, cloud computing can be a powerful tool for transforming flexible classroom structure by 
connecting its stakeholders to multiple programs and applications allowing an innovative presentation of learning standards (U.S. Department of Education, 2017).

In conclusion, this study allowed certain determinants for the implementation of a cloud computing environment at a different type of organization. All the factors define the fundamentals that affect the implementation of strategic cloud-based solution within the school organization that contributes to a piece of developing information and knowledge of cloud computing research. Therefore, this study summarized the critical success factor affecting the cloud computing implementation into three segments: technological, organizational, and environmental attributes which can be a key point as guidelines and step to embrace technological advancement in the Philippines, particularly in the higher education institution sectors.

\section{PRACTICAL IMPLICATIONS}

As part of the research outcome of the current study, cloud computing technology is an advanced tool in transforming the educational system of higher education institutions. The use of cloud computing in the virtual learning of the HEls has been proven effective in streamlining the educational operation in considering the critical success factor with the three-tier model of Technology Environment and Organization framework. This aligns with new educational system development in improving the strategic approach of the learning platform of the HEls into a more advanced and accessible feature of the learning delivery through its stakeholders. Therefore, to realize fully the benefits of cloud computing in the educational system and provide streamlined operation the use of technology principles must be applied in terms of learning, teaching, assessment, and infrastructure capability must be examined in the context of HEls. Thus, cloud computing will offer a wide opportunity in the field of the educational system in shifting into advanced infrastructure development in delivering the services to its stakeholders.

\section{ACKNOWLEDGEMENT}

The author wishes to express her gratitude to the College of Engineering, Computer Studies, and Architecture who was extremely helpful and offered assistance, support, and guidance. Deepest gratitude is also due to the Department of Computer Studies, teachers, and students for contributing their knowledge and assistance this study would not have been successful without their help. The author wishes to express 
the love and gratitude to her beloved family; for their understanding and endless love, through the duration of this research.

\section{REFERENCES}

Abdollahzadehgan, A., Che Hussin, A. R., Gohary, M. M., \&Amini, M. (2013). The organizational critical success factors for adopting cloud computing in SMEs. Journal of Information Systems Research and Innovation, 4(1), 67-74.

Al-Hujran, O., Al-Lozi, E. M., Al-Debei, M. M., \&Maqableh, M. (2018). Challenges of cloud computing adoption from the TOE framework perspective. International Journal of EBusiness Research, 14(3), 77-94. https://doi.org/10.4018/IJEBR.2018070105

Alatresh, S.A, Ali, A.B., Ambarek, \&M.A. (2017). Cloud computing adoption by business organization: a systematic review. Australian Journal of Basic and Applied Sciences, 11(3), 17-28. doi:10.22587/ajbas.2017.11.13.3

Algrari, A. (2017). The impact of cloud-based information systems on organization's performance. IOSR Journal of Computer Engineering (IOSR-JCE)

19(2), 42-46.

Almekhlafi, N., Al-Hashedi, A., Mohsen, A.M., Othman, \&M.T.B.Othman. (2018). Cloud computing awareness among practitioners in Yemeni universities: An exploratory study. Journal of Science and Technology, 23(1), 1-15. doi: 10.20428/jst.23.1.1

Astri, L. Y. (2015). A study literature of critical success factors of cloud computing in organizations. Procedia Computer Science, 59, 188-194. doi: 10.1016/j.procs.2015.07.548

Baker, J. (2011). The technology-organization environment framework (unpublished manuscript). American University of Sharjah, United Arab Emirates.

Bedward, R., \&Fokum, D. (2014). A cloud computing adoption for Jamaican institutions.Paper presented at IEEE SOUTHEASTCON 2014, Lexington, KY, USA.doi:10.1109/SECON.2014.6950693

Buhtz, K., Konig, A., \&Graf-Vlachy, L. (2018). Social influence in technology adoption: taking stock and moving forward.Management Review Quarterly, 68, 3776.doi:10.1007/s11301-017-0133-3

Buyya, R. \& Gill, S. (2018). Sustainable cloud computing: foundations and future directions. Business Technology \& Digital Transformation Strategies, Cutter Consortium, 21(6), 1-9.

Chen, T., Yan, X., Zhang, X., \& Zhao, H. (2012). The research and design of cloud computing security framework. Lecture Notes in Computer Science, 121, 757-763 doi:10.1007/978-3-642-25541-0_95

Dimitrov, M., \& Osman, I. (2012). The impact of cloud computing on organizations in regard to cost and security. Retrieved from https://www.divaportal.org/smash/get/diva2:728880/FULLTEXTo2 
Duan, Q. (2017). Cloud service performance evaluation: status, challenges, and opportunities - a survey from the system modeling perspective. Digital Communications and Networks, 3(2), 101-111. doi: 10.1016/j.dcan.2016.12.002

Enslin, Z. (2012). Introduction to cloud computing and control objectives for information and related technologies (COBIT) - mapped benefits of cloud computing adoption. African Journal of Business Management, 6(41), 10568-10577. doi: 10.5897/ajbm12.584

Fenton, J. (2011). Business continuity and disaster recovery. In B. Halpert (Ed.) Auditing Cloud Computing: A Security and Privacy Guide, (pp. 129-141). John Wiley \& Sons. doi: 10.1002/9781118269091.ch7

Hakim, Z. (2018). Factors that contribute to the resistance to cloud computing adoption by tech companies vs. non-tech companies (unpublished manuscript). Nova Southeastern University, Florida, USA. Retrieved from NSUWorks, College of Engineering and Computing, https://nsuworks.nova.edu/gscis_etd/1034

Jorrigala, V. (2017). Business continuity and disaster recovery plan for information security.Retrieved from https://repository.stcloudstate.edu/msia_etds/44

Kandil, A. M. N. A., Ragheb, M. A., Ragab, A. A., \& Farouk, M. (2018). Examining the effect of TOE model on cloud computing adoption in Egypt. 8th International Conference on Restructuring of the Global Economy, 9(4), 9-10.

Kaur, G., \& Kumar, R. (2015). A review on reliability issues in cloud service. International Journal of Computer Applications, 1, 975-8887. doi: 10.1.1.736.1442

Khan, N., \& Al-Yasiri, A. (2015). Framework for cloud computing adoption: a roadmap for SMEs to cloud migration. International Journal on Cloud Computing: Services and Architecture, 5(5/6), 01-15. doi: 10.5121/ijccsa.2015.5601

Loulloudes N., Sofokleous C., Trihinas D., \&Dikaiakos M. (2015). Enabling interoperable cloud application management through an open source ecosystem. IEEE Internet Computing, 19(3), 54-59. doi: 10.1109/MIC2015.60

Majadi, N. (2012). Cloud Computing-Research Issues and Challenges. In Proceedings of the Global Engineering, Science and Technology Conference 2012. Retrieved from https://www.researchgate.net/profile/Nazia-

Majadi/publication/305473801_Cloud_Computing_Research_Issues_and_Challenges/l inks/57bbb1bbo8aefea8fof45470/Cloud-Computing-Research-Issues-and-

Challenges.pdf

Mckinnie, M. (2016). Cloud computing: TOE adoption factors by service model in manufacturing. Retrieved from http://scholarworks.gsu.edu/bus_admin_diss/68

Menychtas, A., Gomez, S. G., Giessmann, A., Gatzioura, A., Stanoevska, K., Vogel, J., \&Moulos, V. (2012). A marketplace framework for trading cloud-based services. Lecture Notes in Computer Science, 7150, 76-89. doi: 10.1007/978-3-642-28675-9_6

Moore S. (2019). The data center is (almost) dead. Retrieved from https://www.gartner.com/smarterwithgartner/the-data-center-is-almost-dead/ 
Naveed, Q. N., \& Ahmad, N. (2019). Critical success factors (CSFs) for cloud-based eLearning. International Journal of Emerging Technologies in Learning, 14(1), 140-149; 1863-0383. doi: 10.3991/ijet.v14i01.9170

Oliveira, T., \& Martins, M. F. (2010). Information technology adoption models at Firm Level: Review of literature. 4th European Conference on Information Management and Evaluation ECIME 2010, 14(1), 312-322.

Paliwal, S. (2014). Performance challenges in cloud computing. Retrieved from https://www.cmg.org/wp-content/uploads/2014/03/1-Paliwal-Performance-

Challenges-in-Cloud-Computing.pdf

Sadoughi, F., Ali, O., \&Erfannia, L. (2019). Evaluating the factors that influence cloud technology adoption-comparative case analysis of health and non-health sectors: A systematic review. Health Informatics Journal, volume 26(2), 1363-1391. doi: 10.1177/1460458219879340

Schaefer, T., Hofmann, M., Loos, P., \&Fettke, P. (2014). Selecting the right cloud operating model: Privacy and data security in the cloud. ISACA Journal, 3, 1-7.

Sether, A. (2016).Cloud computing benefits.Retrieved from https://ssrn.com/abstract=2781593 or http://dx.doi.org/10.2139/ssrn.2781593

Singh, B. (2013). A systematic review on cloud computing. International Journal of Engineering Research and Technology, Vol.5 Issue.2, 144-148.

Soni V., (2019). AWS Continues to lead, but Azure narrows the gap: Highlights from Right Scale 2019 Report, State of the Cloud Report from Flexera. Retrieved from https://wire19.com/rightscale-2019-state-of-the-cloud-report/

Sriram, I., \&Khajeh-Hosseini, A. (2010). Research agenda in cloud technologies. Retrieved from http://arxiv.org/abs/1001.3259

Stieninger, M., Nedbal, D., Wetzlinger, W., Wagner, G., \& Erskine, M. A. (2014). Impacts on the organizational adoption of cloud computing: a reconceptualization of influencing factors. Procedia Technology, 16, 85-93. https://doi.org/10.1016/j.protcy.2014.10.071

Tam, M.\& Lin, T.T.C. (2012). Exploring the organizational adoption of cloud computing in Singapore. Paper presented at 2012 International Telecommunication Society, Bangkok, Thailand.

Tashkandi, A. A., \& Al-Jabri, I. (2015). Cloud computing adoption by higher education institutions in Saudi Arabia: Analysis based on TOE. Paper presented at 2015 International Conference on Cloud Computing, ICCC 2015. Retrieved from https://doi.org/10.1109/CLOUDCOMP.2015.7149634

The Open Group. (2016). Working for secure Cloud architecture Enabled by Open Systems. Retrieved from https://www.opengroup.org/membership/workgroups/cloudcomputing

Toth, A., \& Ge, M.(2021). A Deployable Data as a Service Architecture for Enterprises. Paper presented at IOTBDS 2021 - 6th International Conference on Internet of Things, Big Data and Security, Masaryk University, Czech Republic, Germany. 
U.S. Department of Education (2017). Role of technology in education: 2017 national education technology plan update. Retrieved from tech.ed.gov

Yoo, S. K., \& Kim, B. Y. (2018). A decision-making model for adopting a cloud computing system. Sustainability, 10(8), 2952. doi: 10.3390/su10082952

\section{Author's Biography}

Amanda Jane C. Menta is an Instructor at Lyceum of the Philippines University Cavite Campus. She received her Master in Information Technology from the Technological University of the Philippines in 2016 and currently undertaking her Ph.D. in Technology Management at the same University. She has been working for academe for almost 5 years and also working as a consultant in some industry-based business in Technology and Security firm in the Philippines. 